\title{
Carbon Nanotube Based Amperometric Biosensor for the Quantitative Detection of Cholesterol
}

\author{
${ }^{1}$ Florentyna Rodrigues, ${ }^{2}$ Devi. S, ${ }^{2}$ Meenakshi.S, ${ }^{2}$ Pandian K and \\ ${ }^{1}$ Palani Perumal* \\ ${ }^{1}$ Center for Advanced Studies in Botany, University of Madras, Chennai, India \\ ${ }^{2}$ Department of Inorganic Chemistry, University of Madras, Chennai, India
}

\begin{abstract}
A high sensitive and stable amperometric biosensor was developed using cholesterol oxidase, chitosan and multiwall carbon nano tubes (MWCNT's) in order to determine total cholesterol in serum samples. Cholesterol oxidase was covalently immobilized on MWCNT's; this enzyme was coated over glassy carbon electrode (GCE) and then a layer of chitosan deposited to prevent enzyme leaching. The ChOX/MWCNT/Chitosan was characterized using fourier transformed-infrared (FT-IR), scanning electron microscopy (SEM), atomic force microscopy (AFM), cyclic voltammetry $(C V)$ and amperometric analyses. These studies indicate immobilization of cholesterol oxidase on MWCNTs, an efficient detection method for cholesterol. The optimum performance of the modified electrode was at $\mathrm{pH} 7.0$ at $40^{\circ} \mathrm{C}$. The optimized biosensor possessed a minimum detection limit of $0.13 \mu \mathrm{M}(\mathrm{S} / \mathrm{N}=3)$ with a fast response time $(\sim 5 s)$ and a wide linear range 0.16 to $9.69 \mathrm{mM}(25$ to $500 \mathrm{mg} / \mathrm{dL})(\mathrm{N}=10, R 2>0.99)$ and $92 \%$ stability up to 7 months. The proposed amperometric biosensor is highly sensitive and exhibits no interference with serum metabolites viz. glucose, uric acid, ascorbic acid and billirubin at their physiological concentrations ranges. Thus, the electrochemical biosensor fabricated in the present investigation is promising for cholesterol detection in blood. Keywords: amperometric biosensor, cholesterol, cholesterol oxidase, multiwalled carbon nanotubes
\end{abstract}

\section{Introduction}

In recent years, an increase in the number diseases related to serum cholesterol levels have highlighted the importance of cholesterol determination and in turn has been reflected in the development of electrochemical devices for quantification of cholesterol. A number of biosensors developed so far for the detection and quantification of cholesterol primarily focus on diagnosing for disorders [1-4]. Cholesterol biosensors based on the amperometric method have been fabricated predominantly of easy miniaturization and real-time monitoring. Apart from this, biosensors based on photometric behavior such as, luminescence, fluorescence and surface plasmon resonance (SPR) have also been developed [5-7]. The principle behind amperometric sensors is that when the enzyme is immobilized onto the surface of an electrode, a redox reaction between the enzyme and the analyte occurs that leads to a subsequent electron transfer between the enzyme and the electrode. This transfer of electrons is transduced into an electrical signal (current). The measurements of $\mathrm{O}_{2}$ consumption or $\mathrm{H}_{2} \mathrm{O}_{2}$ production during cholesterol catalysis by cholesterol oxidase is the strategy frequently used in cholesterol biosensors. Thus, the current generated is directly proportional to the amount of the analyte present $[8,9]$.

Research for a wide range of applications including electronics, optics, catalysis and biological sensors has been largely focused in the area of nanotechnology due to their specific physico-chemical properties. Particularly, metallic nanoparticles such as silver, gold, palladium and platinum have been used extensively due to their unique properties which significantly differ from those presented by the bulk materials [10]. Some of their unique properties are sensitive interface roughness, catalytic and conductive properties, mass transport enhancement and larger specific surface area. The nanoparticles can also increase the rate of electrochemical reaction [10]. Single and multiwalled carbon nanotubes, MWCNTs, CNT-chitosan/GCE, $\mathrm{Fe}_{3} \mathrm{O}_{4}-\mathrm{SiO}_{2} / \mathrm{MWCNT}$, graphene modified graphite electrode, graphene/Pt NPs, Pt/Au ZnO nanorods, NSPANI-AuNP-GR/ITO, AuNPs/Au electrode, graphite-teflon matrix and Pt-Pd bimetallic nanoparticle decorated grapheme are some of the supports which have been used for the transduction of generated biological signals to electrical signals for cholesterol determination [11].

The use of carbon nanotubes (CNT) in fabricating cholesterol biosensors have been reported quite recently as they are quite versatile and provide a number of advantages over the conventionally used materials in biosensor fabrication [5,12-18]. Multiwall carbon nanotubes (MWCNTs) consist of concentric cylindrical shells of graphene sheets arranged around a central hollow area[19]. Owing to their distinctive structure, CNTs acquire extraordinary properties such as high flexibility, large aspect ratio, strong adsorption properties and optimum biocompatibility [20]. Carbon nanotubes are capable of immobilizing biomolecules without diminishing their activity and have attracted scientists to utilize this potential in the construction of sensing devices. Apart from 
this, their nanoscale dimensions, their graphitic surface chemistry, and electrocatalytic properties of carbon nanotubes make them an interesting material for sensing purpose [11].

Many reports show the use of nanomaterials in the form of composite materials for developing cholesterol biosensors. CNTs and NPs of $\mathrm{Au}, \mathrm{Ag}, \mathrm{Pt}, \mathrm{TiO}_{2}$ etc. are commonly used in the form of nanocomposites as enzyme immobilization matrix for biosensor fabrication [21,22]. Most of these biosensors include chitosan as the dispersing medium for CNTs because of its biocompatibility [23,24]. Many biosensors based on CNT electrodes have been reported using carbon nanotubes, it is quite an interesting field of innovation and it reveals a new direction in research on biosensors. In this study, an attempt was made to immobilize cholesterol oxidase onto carbon nanotubes and to fabricate an amperometric biosensor with superior detection in comparison to conventional cholesterol biosensors. The surface confined redox mediator ferrocene carboxylic acid exhibit an excellent electron transfer mediator which facilitate the redox reaction and also act as electrical wiring to connect the cholesterol oxidase and GCE. Detailed studies have been made to correlate the stability and sensitivity of the present biosensor with the previous reported results.

\subsection{REAGENTS AND SOLUTIONS}

\section{Materials And Methods}

Some of the chemicals and solvents like toluene, nitric acid, hydrochloric acid, sulphuric acid, Triton $\mathrm{X}-100$, sodium phosphate monobasic and sodium phosphate dibasic were purchased from SRL Chemicals (India). Ferrocene carboxylic acid, multi-walled carbon nanotubes and cholesterol were procured from SigmaAldrich Chemical Co. (USA). N-hydroxysuccinimide (NHS) and N-ethyl-N'-(3-dimethyl aminopropyl) carbodimide hydrochloride (EDC) were purchased from Tokyo Chemical Industry (Japan). Cholesterol oxidase was obtained from Enterobacter cloacae [25] (Specific Activity $21.87 \mathrm{U} / \mathrm{mg}$ ) was used. All aqueous solutions were prepared with double distilled water and stored at $4{ }^{\circ} \mathrm{C}$.

\subsection{Instrumentation:}

The Perkin-Elmer 360 model IR double beam spectrophotometer was used to record the FT-IR spectra. The spectra were collected from 4000 to $400 \mathrm{~cm}-1$ with $4 \mathrm{~cm}-1$ resolution over 40 scans. All spectra were collected against the background spectrum of $\mathrm{KBr}$. Scanning electron microscopy (SEM) was carried out with field emission JEOL-JSM-6360 instrument, USA. The Cyclic Voltammetry experiment was carried out using, USA and Gamry model 330, USA. Electrochemical experiments were carried out using Gamry, USA model 330 including PV 220 software and a CHI 660A electrochemical instrument, USA. A three electrodes system consisting of GCE of $3 \mathrm{~mm}$ of the geometrical surface area was purchased from BAS, USA. The $\mathrm{Ag} / \mathrm{AgCl}$ with $3 \mathrm{M} \mathrm{KCl}$ was used as a reference electrode and a platinum wire as a counter electrode. The surface of the GCE was polished using the polishing kit from, Bioanalytical system (BAS, USA) the surface of GCE. Initially, the surface of the GCE was cleaned by polishing the surface with 500 micron alumina powder, followed by washing with DD water and finally, it was sonicated for 5 minutes.

\subsection{Purification and Functionalization of Multiwalled Carbon Nanotubes (MWCNTs)}

A mixture containing MWCNTs $(50 \mathrm{mg})$, toluene $(50 \mathrm{~mL})$ and trifluoroacetic acid $(5 \mathrm{~mL})$ was sonicated for $2 \mathrm{~h}$ at $4^{\circ} \mathrm{C}$, centrifuged at $5000 \mathrm{rpm}$ for $15 \mathrm{~min}$ and then the purified MWCNT's washed thrice with toluene. The toluene was removed by drying under vacuum condition for $24 \mathrm{~h}$. Functionalization of MWCNTs was carried out by mixing the CNT in a solution containing nitric and hydrochloric acids in the ratio of $3: 1$ in an ultrasonication bath at $65^{\circ} \mathrm{C}$ for $18 \mathrm{~h}$. The mixture was then centrifuged, supernatant was removed and the nanotubes were air dried.

\subsection{Assembly of ChOx/MWCNTs/Chitosan Glassy Carbon Modified Electrode}

A suspension of MWCNTs was prepared by suspending $5 \mathrm{mg}$ of CNTs in $1.0 \mathrm{~mL}$ solution containing sodium phosphate buffer (0.02M; pH 7.0), ferrocene carboxylic acid (12 mg), NHS (30 mg) and EDC (10 mg). This mixture was ultrasonicated at $4^{\circ} \mathrm{C}$ for an hour. Cholesterol oxidase $(5 \mathrm{mg})$ was added subsequently to the MWCNTs suspension and subjected to ultrasonication at $4^{\circ} \mathrm{C}$ for an hour. The mixture was stored at $4^{\circ} \mathrm{C}$ overnight. Chitosan solution $(0.25 \%$; w/v) was prepared by dissolving chitosan $(0.1 \mathrm{~g})$ in $40 \mathrm{~mL}$ acetate buffer $(0.1 \mathrm{M} ; \mathrm{pH}$ 5.0). The solution was filtered through $11 \mu \mathrm{m}$ filter paper (Whatman, England) to obtain a clear solution and stored at $4^{\circ} \mathrm{C}$.

Prior to modification, the GCE (Glassy Carbon Electrode) was polished with fine emery paper and ultrasonically cleaned for about a minute with water. The electrode was washed thoroughly with double distilled water, dried at room temperature and coated with the MWCNTs solution containing the immobilized enzyme. Once this coat dried, a thin uniform layer of chitosan was applied $(0.25 \%$; w/v) on the electrode. The immobilized enzyme was coated on a glassy carbon electrode followed by a thin layer of chitosan, to construct a working electrode. This working electrode along with $\mathrm{Ag} / \mathrm{AgCl}$ as a reference electrode and $\mathrm{Pt}$ wire as an 
auxiliary electrode were connected through a three terminal electrometer, thus forming the cholesterol biosensor for the estimation of serum cholesterol. The electrode was stored at $4^{\circ} \mathrm{C}$ when it was not in use. All solutions were purged under nitrogen atmosphere for 10 mins before being used.

\subsection{Optimization of Cholesterol Biosensor}

The optimum working conditions of cholesterol biosensor was studied in terms of the current $(\mu \mathrm{A})$ generated in the presence of cholesterol with sodium phosphate buffer $(0.02 \mathrm{M})$ at $\mathrm{pH}$ 's varying from 6.0 to 7.8 . In order to access the optimum temperature, the biosensor was incubated at temperature ranging from 20 to $70^{\circ} \mathrm{C}$ and the readings were taken at intervals of $10^{\circ} \mathrm{C}$. In order to check the sensitivity of the electrode to varying concentrations of the substrate, cholesterol concentrations from 0.646 to $12.9 \mathrm{mM}$ ( 25 to $500 \mathrm{mg} / \mathrm{dL}$ ) were prepared from a stock solution and incubated with the biosensor for 30 minutes at $30^{\circ} \mathrm{C}$. Cyclic voltammetry and amperometry analyses were carried out to study effect of substrate concentration on the biosensor responses.

\subsection{Evaluation of cholesterol biosensor}

The biosensor was evaluated by studying its linearity, sensitivity, minimum detection limit, accuracy, storage and stability. The effect of various serum metabolites such as uric acid, ascorbic acid, bilirubin and glucose found in serum samples were also studied at the normal hyperconcentration.

\section{Results}

The development of biosensors began in the year 1962 with the potentiometric measurement that was coupled with glucose oxidase to measure glucose in blood (Clark and Lyons 1962). This report also introduced the concept of coupling an enzyme with the signal transduction in the creation of a sensor (Clark and Lyons 1962). The success of enzyme-coupled electrochemical sensors is mainly due to the excellent selectivity that enzymes have for analytes of biomedical interest, as well as the simplicity of the electrochemical measurement. Research has been on the rise since the report by Clark et al., (Clark and Lyons 1962) on enzyme based biosensors.

\subsection{Fabrication and Mechanism of ChOx/MWCNTs/Chitosan Modified GCE}

This study, utilizes cholesterol oxidase along with a MWCNT solution, obtained by mixing it in sodium phosphate buffer (0.02M; $\mathrm{pH} 7.0)$, ferrocene carboxylic acid, NHS and EDC for the fabrication of a cholesterol biosensor. Cholesterol oxidase was immobilized on to the MWCNTs, which was then adsorbed on to the glassy carbon electrode (GCE). Chitosan layer was then formed and a final product of ChOx/MWCNT/Chitosan modified GCE was obtained (Fig. 1). The enzyme was covalently attached to MWCNTs modified GCE by activating the - $\mathrm{COOH}$ group in MWCNTs using EDC as the coupling agent, NHS as activator and ferrocene carboxylic acid as the mediator, which catalysed the reaction. The EDC-NHSactivated - $\mathrm{COOH}$ group bound to $\mathrm{NH} 2$ group of $\mathrm{ChOx}$ resulting in the formation of a covalent amide bond (CO$\mathrm{NH}$ ). Cholesterol oxidase was immobilized on to the MWCNTs, and was finally adsorbed on to the glassy carbon electrode (GCE). A chitosan layer was then applied to aid the ChOx/MWCNT IN adhering o the GCE.

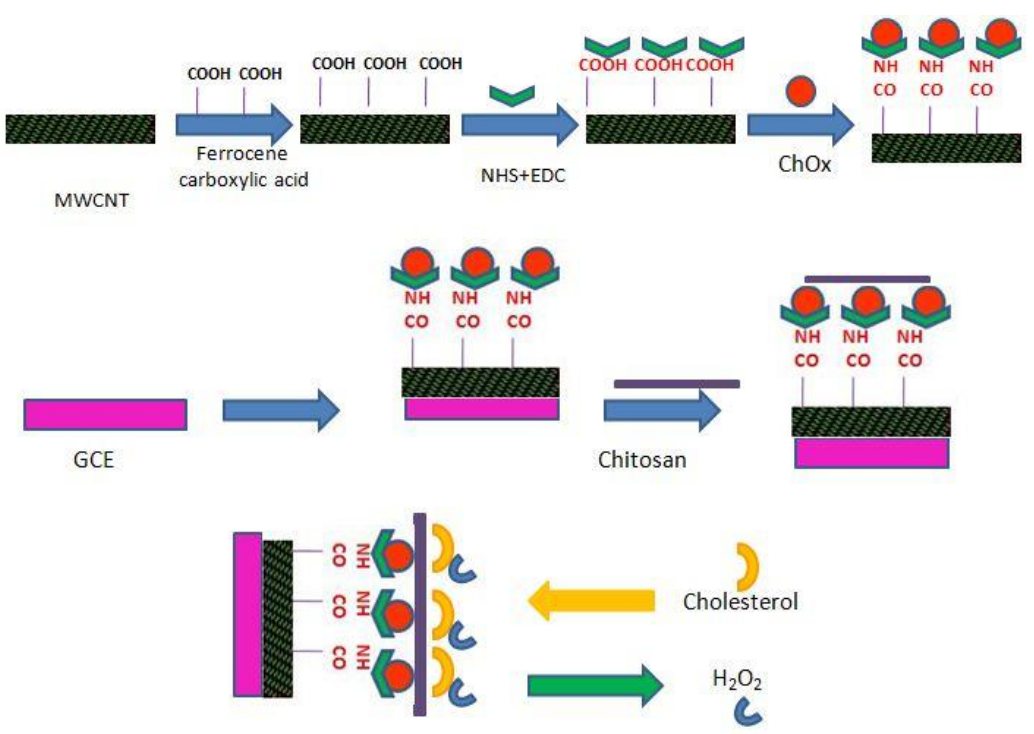

Figure 1 Schematic representation of the fabrication of ChOx/MWCNTs/chitosan modified GCE 


\subsection{Characterization of ChOx/MWCNTs/Chitosan Modified GCE}

The surface functionality of MWCNTs (a) and ChOx/MWCNTs (b) was characterized by Fourier transform infrared spectroscopy (FT-IR). The surface functionality of MWCNTs (a) and ChOx/MWCNTs (b) was characterized by Fourier transform infrared (Fig. 2a). The absorption peaks exhibited at $2250 \mathrm{~cm}-1$ and $1550 \mathrm{~cm}-1$ are the signature peaks of carbon nanotubes. Once the enzyme was immobilized on the MWCNT's, additional peaks appeared at $1649 \mathrm{~cm}-1$ and $3464 \mathrm{~cm}-1$ these corresponded to the carbonyl and hydroxyl moieties of carboxylic acid group. The peak at $1707 \mathrm{~cm}-1$ was attributed to $-\mathrm{C}=\mathrm{O}$ stretching vibrations due to the bound cholesterol oxidase. the carbonyl stretch (amide I band) and $-\mathrm{N}-\mathrm{H}$ bending (amide II band), was responsible for two peaks respectively at $1649 \mathrm{~cm}-1$ and $1645 \mathrm{~cm}-1$. Cholesterol oxidase possessed unique peaks at $1562 \mathrm{~cm}-1$ and $3464 \mathrm{~cm}-1$ which corresponded to the $\mathrm{CH} 3-\mathrm{OH}$ vibration bands. The broad peak obtained at $3464 \mathrm{~cm}-1$ was attributed to amide bond present in cholesterol oxidase (Dhand et al. 2008).

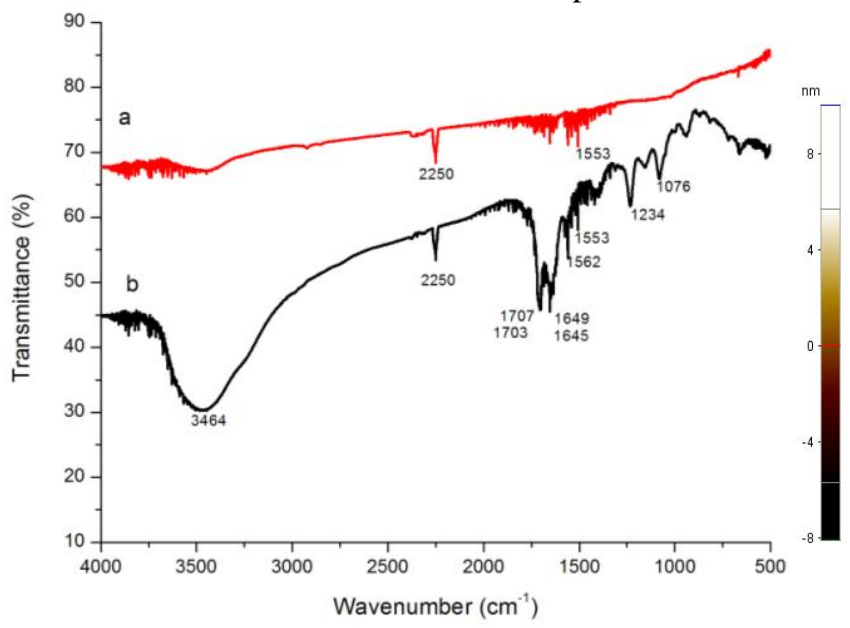

Figure 2a: FT-IR spectra obtained for (a) MWCNTs and (b) MWCNTs with bound cholesterol oxidase

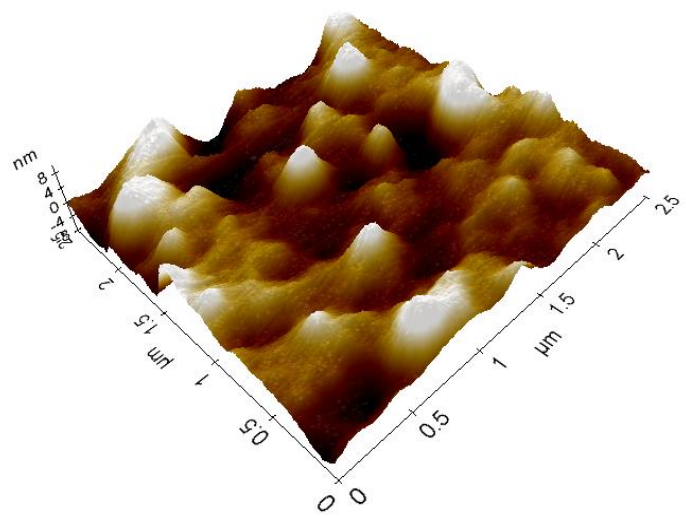

Figure 2b: AFM analysis of immobilized cholesterol oxidase onto MWCNT

The surface topography of ChOx/MWCNTs/chitosan was analyzed with atomic force microscopy (AFM). It displayed irregular matrix topography with a height of $8 \mathrm{~nm}$ (Fig. 2b). The surface morphology of MWCNTs with and without cholesterol oxidase was studied using scanning electron microscopy. A visual change was noticed in the image, after cholesterol oxidase was immobilized. The MWCNTs without cholesterol oxidase showed thread like structures (Fig. 2c) whereas, the MWCNTs bound cholesterol oxidase exhibited the same thread like structures along with round particles. These circular particles might be due to the binding of cholesterol oxidase on the surface of MWCNTs (Fig. 2d).

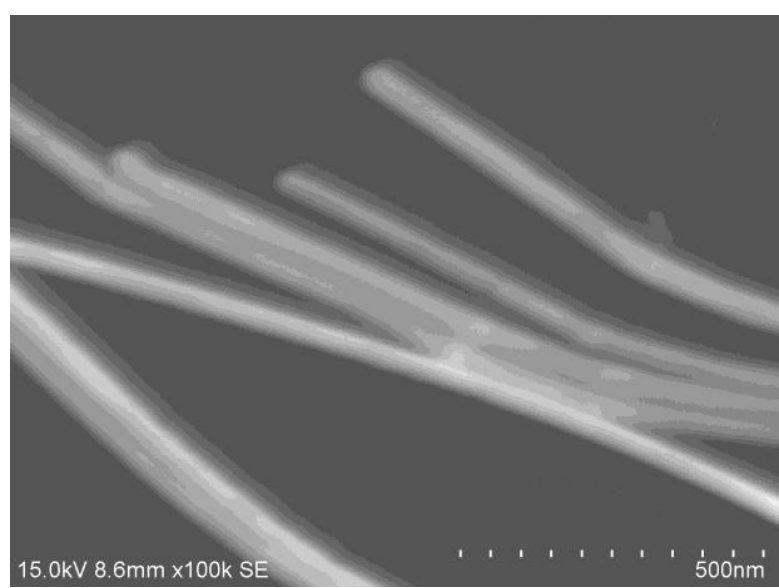

Figure 2c: SEM micrographs of MWCNTs without cholesterol oxidase

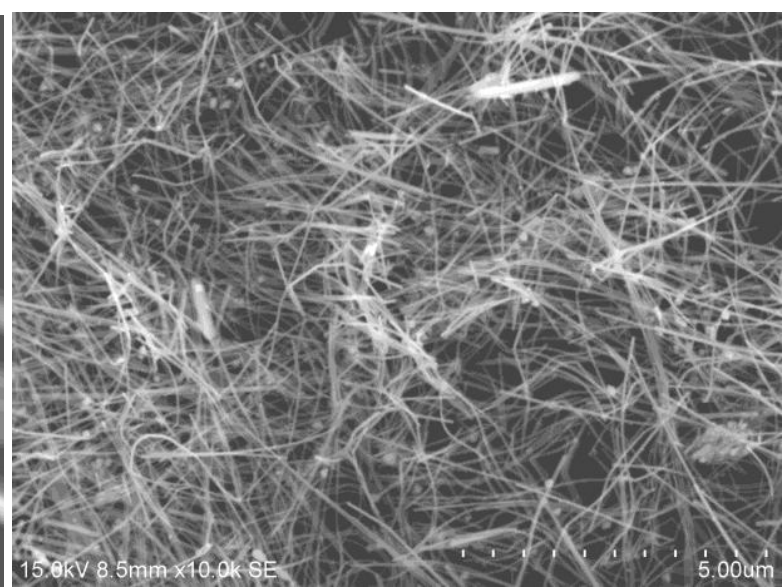

Figure 2d: SEM micrographs of MWCNTs with bound cholesterol oxidase 


\subsection{Electrochemical characteristics of $\mathrm{ChOx} / \mathrm{MWCNTs} / \mathrm{Chitosan}$ film}

In order to compare the effect of the modified GCE to the bare GCE, two voltammograms (Fig. 3 a \& b) were obtained: a) bare GCE (Fig. 3a) and ChOx/MWCNTs/chitosan modified GCE in 0.02M sodium phosphate buffer ( $\mathrm{pH} 7.0$ ) containing $50 \mathrm{mg} / \mathrm{dL}$ cholesterol (Fig. 3b). The corresponding cyclic voltammograms were examined at $50 \mathrm{mVs}^{-1}$ in the potential range of -0.4 to $1.2 \mathrm{~V}$. The corresponding cyclic voltammograms were examined at $50 \mathrm{mVs}^{-1}$ in the potential range of -0.4 to $1.2 \mathrm{~V}$. The bare GCE exhibited no obvious peaks, while the ChOx/MWCNTs/chitosan modified GCE exhibited a sharp peak at $0.8 \mathrm{~V}$ in the presence of cholesterol, this arises as a result of oxidation of the cholesterol added. This can be attributed to the incorporation of cholesterol oxidase in MWCNT-chitosan matrix which leads to enhance the electrocatalytic ability of the modified GCE. In amperometric biosensors electric potential is applied on $\mathrm{H}_{2} \mathrm{O}_{2}$ which get oxidized to produce electrons and the flow of electrons produces current (Lata et al. 2016). The current generated is directly proportional to cholesterol concentration in serum:

$$
\begin{gathered}
\text { Cholesterol }+\mathrm{O}_{2} \stackrel{\text { Cholesterol oxidase }}{\longrightarrow} \text { Cholest-4-en }-3-\text { one }+\mathrm{H}_{2} \mathrm{O}_{2}+\mathrm{O}_{2}+\mathrm{e} \\
\mathrm{H}_{2} \mathrm{O}_{2} \stackrel{\text { Electric Potential }}{\longrightarrow} 2 \mathrm{H}^{+}+\mathrm{O}_{2}+\mathrm{e}
\end{gathered}
$$

It was estimated that $\mathrm{ChOx} / \mathrm{MWCNTs} /$ chitosan modified GCE offered ultimate signal and least noise at $+0.8 \mathrm{~V}$ thus; this value was employed to analytical determinations.

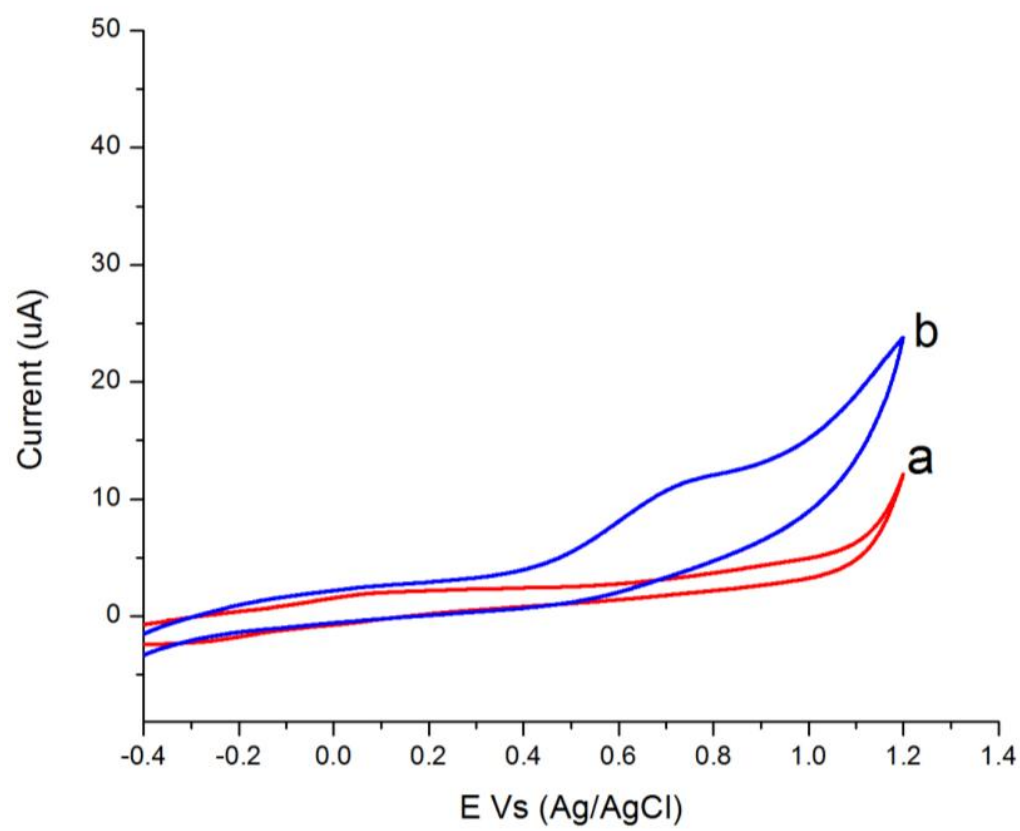

Figure 3 Cyclic Voltammograms of (a) bare, (b) ChOx/MWCNTs/Chitosan modified GCE in the presence of cholesterol via $0.02 \mathrm{M}$ sodium phosphate buffer $(\mathrm{pH} 7.0)$ at a scan rate of $50 \mathrm{mV}^{-1} \mathrm{~s}^{-1}$.

The typical voltammetric responses of the ChOx/MWCNTs/chitosan modified GCE to the addition of varying concentrations of cholesterol $\left((50 \mathrm{mg} / \mathrm{dL}\right.$ to $500 \mathrm{mg} / \mathrm{dL})$ at $50 \mathrm{mVs}^{-1}$ in the potential range of -0.4 to $+1.2 \mathrm{~V}$ (vs. $\mathrm{Ag} / \mathrm{AgCl}$ ) are shown in figure 4 . The obtained $\mathrm{CV}$ profiles clearly evidences that the sensing nature of cholesterol oxidase and cholesterol oxidase incorporated MWCNTs. The reproducibility of the fabricated biosensor was examined by running four $\mathrm{CV}$ cycles at scan rate of $50 \mathrm{mV} / \mathrm{s}^{-1}$. From the cyclic voltammetry studies a sharp peak at $+0.8 \mathrm{~V}$ was observed, due to oxidation of cholesterol. A stable current response was observed at this potential values and hence the present method was utilized for the analytical determination of cholesterol (Fig. 4). A linear graph was plotted using the generated current values obtained from cyclic voltammetric analyses when the concentration of cholesterol was gradually increased. The linear regression equation for ChOx/MWCNTs/Chitosan modified GCE was $\mathrm{y}=0.661(\mathrm{mg} / \mathrm{dL})+42.38$ with a correlation coefficient $\left(\mathrm{R}^{2}\right)$ of 0.9950 as shown in fig. 4 inset. 


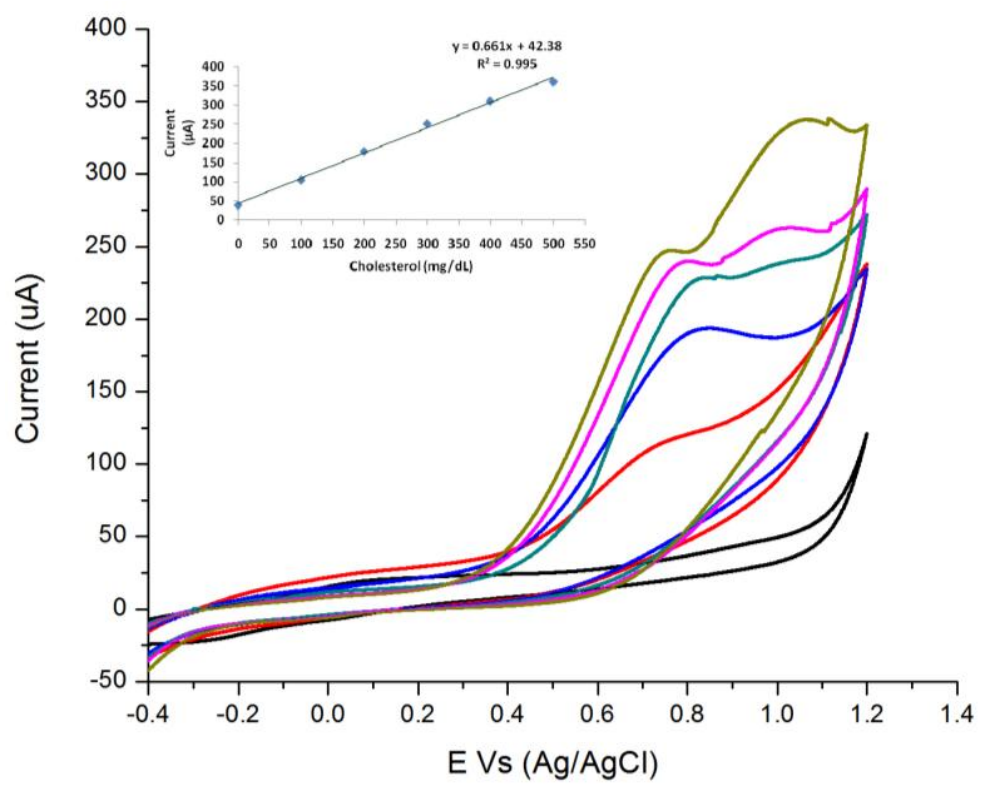

Figure 4 Cyclic Voltammograms obtained with bare and ChOx/MWCNTs/Chitosan modified GCE with different concentration of cholesterol $(100-500 \mathrm{mg} / \mathrm{dL})$ in $0.02 \mathrm{M}$ sodium phosphate buffer $(\mathrm{pH} 7.0)$ at a scan rate of $50 \mathrm{mV} / \mathrm{s}^{-1}$. Inset: Calibration plot of $\mathrm{I}_{\mathrm{p}}$ vs concentration of cholesterol

\subsection{Effect of Working Potential, $\mathrm{pH}$ and Temperature on the functionality of the biosensor}

The response of current with varying applied potential on the biosensor has been shown in Fig. 5a. The working potential was evaluated from $0.2 \mathrm{~V}$ to $1.4 \mathrm{~V}$ (vs. $\mathrm{Ag} / \mathrm{AgCl}$ ). With the increase in working potential, increase in steady-state current response was observed. Initially, it exhibited a significant increase in current value from $+0.2 \mathrm{~V}$ to $+0.8 \mathrm{~V}$ and then declined slightly after $+0.8 \mathrm{~V}$. Therefore, $+0.8 \mathrm{~V}$ was selected as the working potential for detection of cholesterol by the biosensor.

The electrochemical response of ChOx/MWCNTs/chitosan modified GCE was evaluated at different pH's (4 to 9) using cyclic voltammetric analysis. The biosensor generated comparatively higher current when the biosensor maintained at $\mathrm{pH} 7.0$ than the other $\mathrm{pH}$ 's. Variation in peak current (Ip) was observed when $\mathrm{pH}$ was changed (Fig. 5b). The potential peak current was observed at $\mathrm{pH}$ 7.0.

Similarly, the effect of temperature on the electrochemical response of ChOx/MWCNTs/chitosan modified GCE was obtained. The sensor was stable up to a temperature of $40^{\circ} \mathrm{C}$ after which, there was a gradual decrease in the current generated as shown in Fig. 5c. This observation is due to the denaturation of the enzyme as temperature is increased and agrees with earlier reports made [26-29].

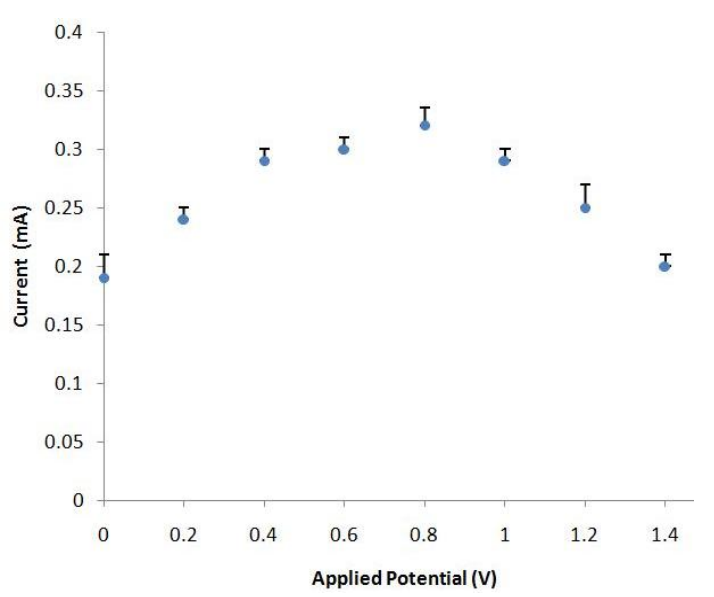

Figure 5a Amperometric response of the working potential of

ChOx/MWCNTs/Chitosan modified

GCE at an applied potential between 0.2

to $1.4 \mathrm{~V}$ in the presence of cholesterol

$(50 \mathrm{mg} / \mathrm{dL})$ via $0.02 \mathrm{M}$ sodium phosphate

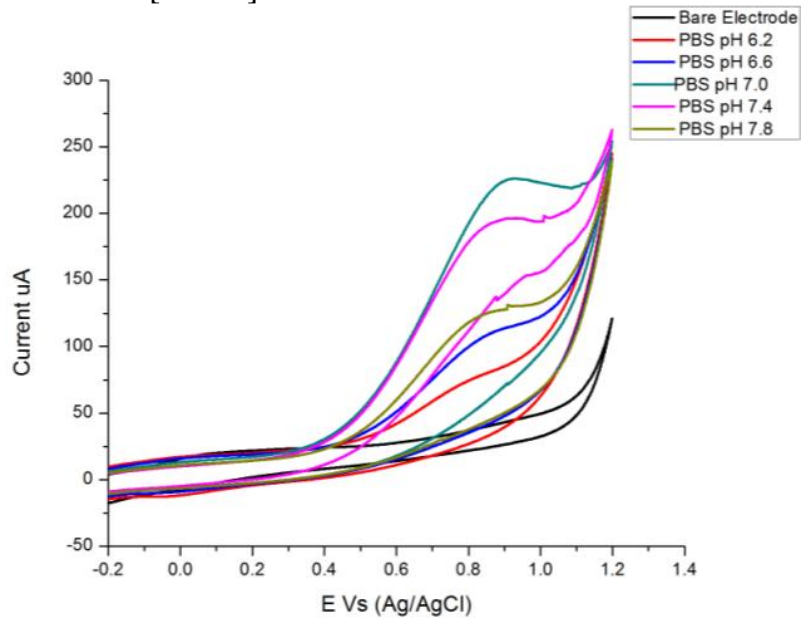

Figure 5b Cyclic Voltammograms obtained with bare and

ChOx/MWCNTs/Chitosan modified

GCE with different concentration of cholesterol $(100-500 \mathrm{mg} / \mathrm{dL})$ in $0.02 \mathrm{M}$ sodium phosphate buffer ( $\mathrm{Ph} 6.2$ to 7.8) 


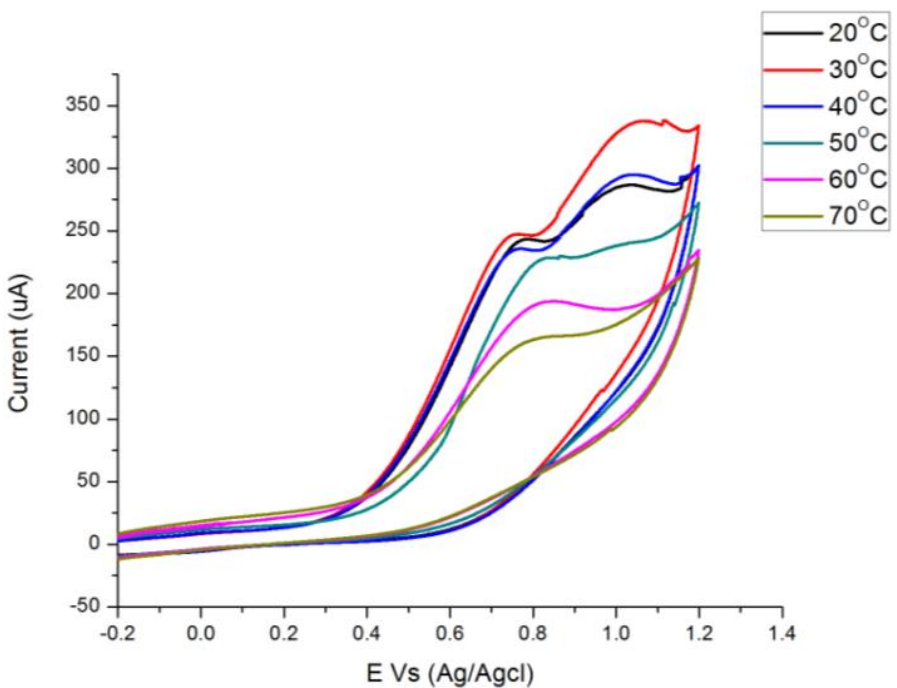

Figure 5c. Cyclic Voltammograms obtained with bare and ChOx/MWCNTs/Chitosan modified GCE with cholesterol $(100-500 \mathrm{mg} / \mathrm{dL})$ in $0.02 \mathrm{M}$ sodium phosphate buffer $(\mathrm{pH} 7.0)$ with various temperatures $\left(20-70^{\circ} \mathrm{C}\right)$ at a scan rate of $50 \mathrm{mV} / \mathrm{s}$.

\subsection{Amperometric detection of cholesterol with the fabricated biosensor (ChOx/MWCNTs/Chitosan modified GCE)}

The detection of cholesterol by the fabricated biosensor was determined amperometrically by measuring the current generated with the addition of cholesterol to the sensor in a gradient manner 25 to 500 $\mathrm{mg} / \mathrm{dL}(0.1615$ to $9.69 \mathrm{mM})$. The cholesterol was injected to the biosensor at $10 \mu \mathrm{l}$ every 25 seconds at $30^{\circ} \mathrm{C}$, the biosensor was polarized at $+0.8 \mathrm{~V}$ under constant stirring in sodium phosphate buffer and the current approach gave a hyperbolic curve between current response and cholesterol concentration (Fig. 6). A significant response was observed up to a concentration of $500 \mathrm{mg} / \mathrm{dL}(9.69 \mathrm{mM})$. The fabricated biosensor achieved $95 \%$ of steady state current in less than 5s. The calibration curve was found to be linear between electrocatalytic current and cholesterol concentration. The linear regression equation of $\mathrm{y}(\mu \mathrm{A})=0.077(\mathrm{mg} / \mathrm{dL})+55.59$ with a correlation coefficient $\left(\mathrm{R}^{2}\right)$ of 0.992 (Inset Fig. 6).

The Amperometric detection of cholesterol with the fabricated biosensor (ChOx/MWCNTs/Chitosan modified GCE) exhibited a hyperbolic curve between current response and cholesterol concentration (Figure 6). The values obtained from the amperometric experiments and its calibration curve clearly demonstrated the advantages such as high sensitivity, low detection limit $(0.13 \mu \mathrm{M})$ and wide linear range achieved by the $\mathrm{ChOx} / \mathrm{MWCNTs} /$ chitosan modified GCE fabricated in the present study for cholesterol detection in comparison to the previous cholesterol biosensors (Wang et al. 2012; Singh et al. 2013; Zhu et al. 2013b; Cao et al. 2013).

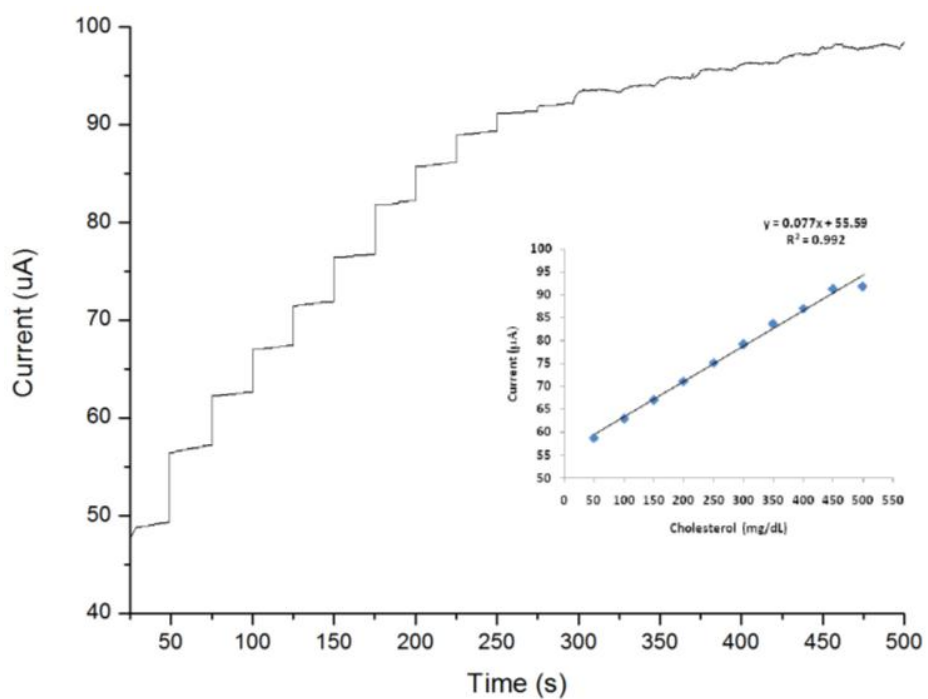

Figure 6 Amperometric detection of ChOx/MWCNTs/Chitosan modified GCE at an applied potential $0.6 \mathrm{~V}$ to subsequent addition of increasing concentrations of cholesterol $(50-500 \mathrm{mg} / \mathrm{dL})$ in the presence of $0.02 \mathrm{M}$ sodium phosphate buffer ( $\mathrm{pH} 7.0)$ 


\subsection{Evaluation of the ChOx/MWCNTs/Chitosan modified GCE}

\subsubsection{Accuracy}

The accuracy of the cholesterol biosensor (ChOx/MWCNTs/chitosan modified GCE) fabricated in the present study was evaluated and compared with the conventional colorimetric based method. The measurement of cholesterol by these methods was performed with a solution containing 213,345 and $407 \mathrm{mg} / \mathrm{dL}$. The detection accuracy of these methods did not differ from each other (Table 1) thus demonstrating excellent accuracy.

Table 1: Measurement of cholesterol by ChOx/MWCNTs/Chitosan modified GCE $v s$ colorimetric method

\begin{tabular}{|c|c|c|c|c|c|c|}
\hline \multirow{2}{*}{$\begin{array}{l}\text { Concentration of } \\
\text { Cholesterol } \\
\text { Used (mg) } \\
\text { (mg/dL) }\end{array}$} & \multicolumn{3}{|c|}{ Measurement } & \multirow{2}{*}{$\begin{array}{c}\text { Mean } \\
(\boldsymbol{\mu} \mathbf{A})\end{array}$} & \multirow[b]{2}{*}{$\begin{array}{l}\text { Standard } \\
\text { deviation }\end{array}$} & \multirow{2}{*}{$\begin{array}{l}\text { Concentration of } \\
\text { Cholesterol } \\
\text { Used } \\
(\mathbf{m g} / \mathbf{d L})\end{array}$} \\
\hline & $\begin{array}{c}1 \\
(\boldsymbol{\mu A})\end{array}$ & $\begin{array}{c}2 \\
(\boldsymbol{\mu A})\end{array}$ & $\begin{array}{c}3 \\
(\mu \mathrm{A})\end{array}$ & & & \\
\hline \multicolumn{7}{|c|}{ Cholesterol measurement with ChOx/MWCNTs/Chitosan modified GCE } \\
\hline 213 & 659.5 & 659.6 & 659 & 659.36 & 0.321 & 213 \\
\hline 345 & 820.47 & 820.8 & 820.3 & 820.52 & 0.254 & 345 \\
\hline 407 & 896.2 & 896.7 & 896 & 896.3 & 0.361 & 407 \\
\hline \multicolumn{7}{|c|}{ Cholesterol measurement with conventional colorimetric method OD at $640 \mathrm{~nm}$} \\
\hline $\begin{array}{l}\text { Concentration of } \\
\text { cholesterol }\end{array}$ & $\begin{array}{c}1 \\
\text { OD at } 640\end{array}$ & $\begin{array}{c}2 \\
\text { OD at } 640\end{array}$ & $\begin{array}{c}3 \\
\text { OD at } 640\end{array}$ & $\begin{array}{l}\text { Mean } \\
\text { (OD) }\end{array}$ & $\begin{array}{l}\text { Standard } \\
\text { deviation }\end{array}$ & $\begin{array}{l}\text { Concentration of } \\
\text { cholesterol }\end{array}$ \\
\hline 213 & 0.2123 & 0.2197 & 0.2105 & 0.2141 & 0.005 & 213 \\
\hline 345 & 0.3403 & 0.3389 & 0.3422 & 0.3404 & 0.002 & 345 \\
\hline 407 & 0.4055 & 0.4081 & 0.403 & 0.4055 & 0.003 & 407 \\
\hline
\end{tabular}

\subsubsection{Precision}

The concentration of total cholesterol was calculated on the same day (within batch) and in the same sample after storage at $4^{\circ} \mathrm{C}$ for one week (between batches) in the serum sample repeatedly to examine the reproducible nature of the current biosensor. The values for coefficients of variation (CVs) were $<0.21 \%$ and < $0.24 \%$ for within batch and between batches, respectively (Table 2). The results were far better than various earlier reported methods (Table 3).

Table 2: Within batch and between batches coefficients of variation for determination of total cholesterol in samples

\begin{tabular}{|c|c|c|}
\hline $\begin{array}{c}\text { n } \\
\text { Number of Experiments }\end{array}$ & $\begin{array}{c}\text { Total Cholesterol (mg/dL) } \\
\text { (mean of experiments } \pm \text { Standard }\end{array}$ & Coefficient of Variance \\
\hline Within Batch (5) & $209.786 \pm 0.4$ & 0.21 \\
\hline Between Batches (5) & $209.556 \pm 0.5$ & 0.24 \\
\hline
\end{tabular}

\subsubsection{Effect of serum metabolites on the functionality of fabricated biosensor}

The accuracy of the ChOx/MWCNT's/chitosan modified GCE for determination of cholesterol was evaluated by incubating the fabricated biosensor with cholesterol in the presence of physiological concentration of bilirubin $(0.02 \mathrm{mg} / \mathrm{mL})$, glucose $(1.40 \mathrm{mg} / \mathrm{mL})$, uric acid $(0.07 \mathrm{mg} / \mathrm{mL})$ and ascorbic acid $(0.02 \mathrm{mg} / \mathrm{mL})$. These metabolites did not generate current and the generation of current was observed only with cholesterol. (Fig. 7)

\subsubsection{Stability and Storage}

The cholesterol biosensor (ChOx/MWCNTs/Chitosan modified GCE) was stored at $4^{\circ} \mathrm{C}$ for 7 months and evaluated for its stability at the interval of every month. The functionality of the biosensor was not affected by storage up to 4 months. There was a gradual decrease in the functionality of biosensors stored for above 4 months. (Fig. 8) The biosensors lost 5, 7 and $8 \%$ of their efficiency when stored at 5,6 and 7 months respectively. 
Table 3: Comparison of analytical performances of different biosensors for the determination of cholesterol

\begin{tabular}{|c|c|c|c|c|c|}
\hline Nano material used & $\begin{array}{l}\text { Sensing } \\
\text { element }\end{array}$ & Linearity & $\begin{array}{c}\text { Detection } \\
\text { limit }\end{array}$ & Stability & Reference \\
\hline AuNp's & ChOx & $0.04-0.22 \mathrm{mM}$ & $346 \mu \mathrm{M}$ & $\sim 95 \%$ after1month & [30] \\
\hline MWCNT'S & ChOx & $\begin{array}{c}4.68 \times 10^{-5}- \\
22.79 \times 10^{-4} \mathrm{M}\end{array}$ & $4.68 \times 10^{-5} \mathrm{M}$ & Not reported & [19] \\
\hline $\begin{array}{c}\text { Nano porous gold } \\
\text { network }\end{array}$ & $\begin{array}{c}\text { ChOx, ChEt, } \\
\text { HRP }\end{array}$ & $300 \mathrm{mg} / \mathrm{dL}$ & $0.5 \mathrm{mg} / \mathrm{dL}$ & $95 \%$ after 60 days & [31] \\
\hline AuNp's & ChOx, GOx & $0.002-1.0 \mathrm{mM}$ & $0.6 \mu \mathrm{M}$ & $88.7 \%$ after three weeks & [32] \\
\hline AuNp's & ChOx & $3.3 \mu \mathrm{M}-1.0 \mathrm{mM}$ & $1.1 \mu \mathrm{M}$ & $\begin{array}{c}80.2 \% \text { retained after one } \\
\text { week }\end{array}$ & [24] \\
\hline PtNP's & ChOx & Up to $1.4 \mathrm{mM}$ & $0.1 \mathrm{~nm}$ & $91 \%$ after 15 days & [33] \\
\hline AuPt alloy NPs & ChOx & $0.05-11.2 \mathrm{mM}$ & $10 \mu \mathrm{M}$ & $90 \%$ after 30 days & [34] \\
\hline Cu2O NP's & ChOx, ChEt, & $10-450 \mathrm{mg} / \mathrm{dL}$ & $15.9 \mathrm{mg} / \mathrm{dL}$ & $82 \%$ after 60 days & [35] \\
\hline CNT's & ChOx & $50-400 \mathrm{mg} / \mathrm{dL}$ & $0.25 \mathrm{mM}$ & $80 \%$ after one month & {$[36]$} \\
\hline ZnO Nano rods & ChOx & $0.001-10 \mathrm{mM}$ & n.r & $\sim 90 \%$ after20days & [37] \\
\hline CNT's & ChOx & $\begin{array}{l}50-300 \mathrm{mg} / \mathrm{dl} \\
\text { approximately, }\end{array}$ & $\begin{array}{c}0.22 \\
\mu \mathrm{A} / \mathrm{mg} / \mathrm{dL} \\
\end{array}$ & 1 month & [38] \\
\hline PANI Nano spheres & ChOx & $25-500 \mathrm{mg} / \mathrm{dL}$ & $67 \mathrm{mg} / \mathrm{dL}$ & 12 weeks & [39] \\
\hline Epoxy resin membrane & $\mathrm{ChOx}$ & 1.0 to $8.0 \mathrm{mM}$ & $1.0 \mathrm{mM}$ & 6 months & [40] \\
\hline AuNPs-MWCNTs & ChOx & $0.0100-500 \mathrm{mmol} / \mathrm{L}$ & $4.3 \mathrm{mmol} / \mathrm{L}$ & $95 \%$ in 2 weeks & [21] \\
\hline PANI-MWCNT/ITO & ChOx & 1.29 to $12.93 \mathrm{mM}$ & $6800 \mathrm{nA} / \mathrm{mM}$ & 12 weeks & [41] \\
\hline $\begin{array}{c}\text { Pt-Pd chitosan- } \\
\text { graphene nanocomposite }\end{array}$ & ChOx & $0.02-5.2 \mathrm{mM}$ & $0.75 \mu \mathrm{M}$ & $92.1 \%$ after 35 days & [42] \\
\hline AuNPs/c-MWCNTs & $\begin{array}{c}\mathrm{ChE} / \mathrm{ChO} / \mathrm{HR} \\
\mathrm{P} \\
\end{array}$ & $0.5 \mathrm{mg} / \mathrm{dL}-250 \mathrm{mg} / \mathrm{dL}$ & $0.5 \mathrm{mg} / \mathrm{dL}$ & 60days & [11] \\
\hline CHOX MWCNTs & CHOX & $0.1615 \mathrm{mM}-9.69 \mathrm{mM}$ & $0.13 \mu \mathrm{M}$ & $\sim 92 \%$ after 7 months & $\begin{array}{c}\text { This } \\
\text { Work }\end{array}$ \\
\hline
\end{tabular}

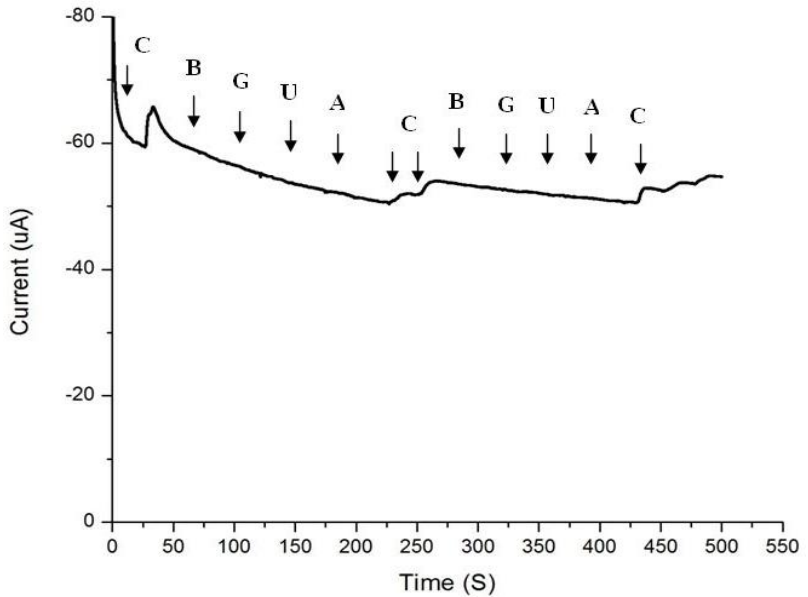

Figure 7: Amperometric response of several interfering compounds at ChOx/MWCNTs/Chitosan modified GCE in the presence of cholesterol via $0.02 \mathrm{M}$ sodium phosphate buffer ( $\mathrm{pH} 7.0)$

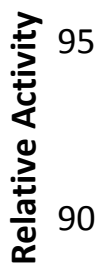

Figure 8: Stability of

ChoX/MWCNT/Chitosan modified GCE over seven months

Legend: Uric acid (U): $0.07 \mathrm{mg} / \mathrm{mL}$; Ascorbic acid (A): $0.02 \mathrm{mg} / \mathrm{mL}$ Bilirubin (B): $0.02 \mathrm{mg} / \mathrm{mL}$; Glucose (G): $1.40 \mathrm{mg} / \mathrm{mL}$; Cholesterol (C): $0.50 \mathrm{mg} / \mathrm{mL}$

\section{Conclusion}

The success of any biosensor developed for medical importance depends on how it works in the presence of other interfering molecules and how stable they are? The fabricated biosensor in the present study was evaluated for its functionality in the presence of serum metabolites such as glucose, uric acid, ascorbic acid and bilirubin at their physiological concentration. Practically there was no interference from serum metabolites on the functionality of the fabricated biosensor, it was found to be stable over a period of 7 months when stored at $4^{\circ} \mathrm{C}$. The optimum working range of $\mathrm{pH}$ and temperature make it versatile and easy to use for serum samples. Its fast response time $(\sim 5 \mathrm{~s})$ and high sensitivity $(0.13 \mu \mathrm{M})$ are superior to conventional cholesterol biosensors. The accuracy, precision, effect of serum metabolites on the functionality of fabricated biosensor, stability and 
storage of the fabricated biosensor exhibited superior results in comparison to existing sensors, as depicted in the results. Thus, this biosensor is desirable due to its enhanced working parameters in comparison to other cholesterol biosensors.

\section{Acknowledgement}

The Authors wish to thank the University Grants Commission (UGC-BSR) for funding this work. The National Centre for Nanoscience and Nanotechnology, University of Madras, for providing the SEM facility and the Department of Inorganic Chemistry, University of Madras, for providing the FT-IR facility.

Funding: This study was funded by The University Grants Commission (GCCO/A-2/UGC-BSR/2012/384).

\section{References}

[1] C. Bongiovanni, T. Ferri, A. Poscia, M. Varalli, R. Santucci, A. Desideri, An electrochemical multienzymatic biosensor for determination of cholesterol, Bioelectrochemistry. 54 (2001) 17-22.

[2] J.C. Vidal, E. Garcia-Ruiz, J. Espuelas, T. Aramendia, J.R. Castillo, Comparison of biosensors based on entrapment of cholesterol oxidase and cholesterol esterase in electropolymerized films of polypyrrole and diaminonaphthalene derivatives for amperometric determination of cholesterol, Anal. Bioanal. Chem. 377 (2003) 273-280.

[3] M. Yang, Y. Yang, H. Yang, G. Shen, R. Yu, Layer-by-layer self-assembled multilayer films of carbon nanotubes and platinum nanoparticles with polyelectrolyte for the fabrication of biosensors., Biomaterials. 27 (2006) 246-55.

[4] K.M. Manesh, P. Santhosh, A.I. Gopalan, K.-P. Lee, Silica-Polyaniline Based Bienzyme Cholesterol Biosensor: Fabrication and Characterization, Electroanalysis. 22 (2010) 2467-2474.

[5] S.K. Arya, M. Datta, B.D. Malhotra, Recent advances in cholesterol biosensor, Biosens. Bioelectron. 23 (2008) 1083-1100.

[6] K.-E. Kim, T.G. Kim, Y.-M. Sung, Fluorescent cholesterol sensing using enzyme-modified CdSe/ZnS quantum dots, $J$. Nanoparticle Res. 14 (2012) 1-9.

[7] M.D. Marazuela, B. Cuesta, M.C. Moreno-Bondi, A. Quejido, Free cholesterol fiber-optic biosensor for serum samples with simplex optimization, Biosens. Bioelectron. 12 (1997) 233-240.

[8] S. Brahim, D. Narinesingh, A. Guiseppi-Elie, Polypyrrole-hydrogel composites for the construction of clinically important biosensors, Biosens. Bioelectron. 17 (2002) 53-59.

[9] A. Umar, M.M. Rahman, A. Al-Hajry, Y.-B. Hahn, Highly-sensitive cholesterol biosensor based on well-crystallized flower-shaped ZnO nanostructures., Talanta. 78 (2009) 284-9.

[10] B. Ertan, T. Eren, I. Ermiş, H. Saral, N. Atar, M.L. Yola, Sensitive analysis of simazine based on platinum nanoparticles on polyoxometalate/multi-walled carbon nanotubes, J. Colloid Interface Sci. 470 (2016) 14-21.

[11] K. Lata, V. Dhull, V. Hooda, Fabrication and Optimization of ChE / ChO / HRP-AuNPs / c-MWCNTs Based Silver Electrode for Determining Total Cholesterol in Serum, Biochem. Res. Int. 2016 (2016) 11.

[12] J. Yang, H. Lee, M. Cho, J. Nam, Y. Lee, Nonenzymatic cholesterol sensor based on spontaneous deposition of platinum nanoparticles on layer-by-layer assembled CNT thin film, Sensors Actuators, B Chem. 171-172 (2012) 374-379.

[13] P.R. Solanki, A. Kaushik, A. a. Ansari, a. Tiwari, B.D. Malhotra, Multi-walled carbon nanotubes/sol-gel-derived silica/chitosan nanobiocomposite for total cholesterol sensor, Sensors Actuators, B Chem. 137 (2009) 727-735.

[14] M. Guo, J. Chen, J. Li, L. Nie, S. Yao, Carbon nanotubes-based amperometric cholesterol biosensor fabricated through layer-bylayer technique, Electroanalysis. 16 (2004) 1992-1998.

[15] G. Li, J.M. Liao, G.Q. Hu, N.Z. Ma, P.J. Wu, Study of carbon nanotube modified biosensor for monitoring total cholesterol in blood, Biosens. Bioelectron. 20 (2005) 2140-2144.

[16] X. Tan, M. Li, P. Cai, L. Luo, X. Zou, An amperometric cholesterol biosensor based on multiwalled carbon nanotubes and organically modified sol-gel/chitosan hybrid composite film, Anal. Biochem. 337 (2005) 111-120.

[17] S. Soylemez, F.E. Kanik, S. Tarkuc, Y.A. Udum, L. Toppare, A sepiolite modified conducting polymer based biosensor., Colloids Surf. B. Biointerfaces. 111 (2013) 549-55.

[18] S. Soylemez, F. Ekiz Kanik, M. Ileri, S.O. Hacioglu, L. Toppare, Development of a novel biosensor based on a conducting polymer., Talanta. 118 (2014) 84-9.

[19] J.Y. Yang, Y. Li, S.M. Chen, K.C. Lin, Fabrication of a cholesterol biosensor based on cholesterol oxidase and multiwall carbon nanotube hybrid composites, Int. J. Electrochem. Sci. 6 (2011) 2223-2234.

[20] P.M. Ajayan, Nanotubes from Carbon, Chem. Rev. 99 (1999) 1787-1800.

[21] L. Zhu, L. Xu, L. Tan, H. Tan, S. Yang, S. Yao, Direct electrochemistry of cholesterol oxidase immobilized on gold nanoparticlesdecorated multiwalled carbon nanotubes and cholesterol sensing, Talanta. 106 (2013) 192-199.

[22] P. Miao, K. Han, H. Sun, J. Yin, J. Zhao, B. Wang, Y. Tang, Melamine Functionalized Silver Nanoparticles as the Probe for Electrochemical Sensing of Clenbuterol, ACS Appl. Mater. Interfaces. 6 (2014) 8667-8672.

[23] R. Rawal, C.S. Pundir, Development of an amperometric sulfite biosensor based on SO(x)/PBNPs/PPY modified ITO electrode., Int. J. Biol. Macromol. 51 (2012) 449-55.

[24] M. Zhang, R. Yuan, Y. Chai, S. Chen, H. Zhong, C. Wang, Y. Cheng, A biosensor for cholesterol based on gold nanoparticlescatalyzed luminol electrogenerated chemiluminescence., Biosens. Bioelectron. 32 (2012) 288-92.

[25] F. Rodrigues and P.Palani Purification and Characterization of Cholesterol Oxidase from a Novel Source - Enterobacter cloacae, IOSR J. Environ. Sci. Ver. I. 10 (2016) 2319-2399.

[26] Suman, C.S. Pundir, Co-immobilization of cholesterol esterase, cholesterol oxidase and peroxidase onto alkylamine glass beads for measurement of total cholesterol in serum, Curr. Appl. Phys. 3 (2003) 129-133.

[27] S. Singh, A. Chaubey, B.. Malhotra, Amperometric cholesterol biosensor based on immobilized cholesterol esterase and cholesterol oxidase on conducting polypyrrole films, Anal. Chim. Acta. 502 (2004) 229-234.

[28] J.-C. Vidal, J. Espuelas, J.-R. Castillo, Amperometric cholesterol biosensor based on in situ reconstituted cholesterol oxidase on an immobilized monolayer of flavin adenine dinucleotide cofactor., Anal. Biochem. 333 (2004) 88-98.

[29] V. Hooda, A. Gahlaut, H. Kumar, C.S. Pundir, Biosensor based on enzyme coupled PVC reaction cell for electrochemical measurement of serum total cholesterol, Sensors Actuators B Chem. 136 (2009) 235-241.

[30] U. Saxena, M. Chakraborty, P. Goswami, Covalent immobilization of cholesterol oxidase on self-assembled gold nanoparticles for highly sensitive amperometric detection of cholesterol in real samples., Biosens. Bioelectron. 26 (2011) 3037-43.

[31] A. Ahmadalinezhad, A. Chen, High-performance electrochemical biosensor for the detection of total cholesterol., Biosens. 
Bioelectron. 26 (2011) 4508-13.

[32] Q. Huang, Y. An, L. Tang, X. Jiang, H. Chen, W. Bi, Z. Wang, W. Zhang, A dual enzymatic-biosensor for simultaneous determination of glucose and cholesterol in serum and peritoneal macrophages of diabetic mice: evaluation of the diabetesaccelerated atherosclerosis risk., Anal. Chim. Acta. 707 (2011) 135-41.

[33] B.K. Jena, C.R. Raj, Enzyme integrated silicate-Pt nanoparticle architecture: a versatile biosensing platform., Biosens. Bioelectron. 26 (2011) 2960-6.

[34] A. Safavi, F. Farjami, Electrodeposition of gold-platinum alloy nanoparticles on ionic liquid-chitosan composite film and its application in fabricating an amperometric cholesterol biosensor., Biosens. Bioelectron. 26 (2011) $2547-52$.

[35] J. Singh, M. Srivastava, A. Roychoudhury, D.W. Lee, S.H. Lee, B.D. Malhotra, Bienzyme-Functionalized Monodispersed Biocompatible Cuprous Oxide/Chitosan Nanocomposite Platform for Biomedical Application, J. Phys. Chem. B. 117 (2013) 141152.

[36] A. Wisitsoraat, P. Sritongkham, C. Karuwan, D. Phokharatkul, T. Maturos, A. Tuantranont, Fast cholesterol detection using flow injection microfluidic device with functionalized carbon nanotubes based electrochemical sensor., Biosens. Bioelectron. 26 (2010) $1514-20$.

[37] M.Q. Israr, J.R. Sadaf, M.H. Asif, O. Nur, M. Willander, B. Danielsson, Potentiometric cholesterol biosensor based on ZnO nanorods chemically grown on Ag wire, Thin Solid Films. 519 (2010) 1106-1109.

[38] A. Wisitsoraat, C. Karuwan, K. Wong-ek, D. Phokharatkul, P. Sritongkham, A. Tuantranont, High sensitivity electrochemical cholesterol sensor utilizing a vertically aligned carbon nanotube electrode with electropolymerized enzyme immobilization, Sensors. 9 (2009) 8658-8668.

[39] C. Dhand, M. Das, G. Sumana, A.K. Srivastava, M.K. Pandey, C.G. Kim, M. Datta, B.D. Malhotra, Preparation, characterization and application of polyaniline nanospheres to biosensing, Nanoscale. 2 (2010) 747-754.

[40] C.S. Pundir, J. Narang, N. Chauhan, P. Sharma, R. Sharma, An amperometric cholesterol biosensor based on epoxy resin membrane bound cholesterol oxidase, Indian J. Med. Res. 136 (2012) 633-640.

[41] C. Dhand, S.K. Arya, M. Datta, B.D. Malhotra, Polyaniline-carbon nanotube composite film for cholesterol biosensor, Anal. Biochem. 383 (2008) 194-199.

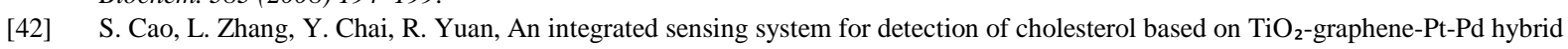
nanocomposites., Biosens. Bioelectron. 42 (2013) 532-8. 